NBER WORKING PAPER SERIES

THE MILDEST RECESSION: OUTPUT, PROFITS, AND STOCK PRICES AS THE U.S. EMERGES FROM THE 2001 RECESSION

\author{
William D. Nordhaus \\ Working Paper 8938 \\ http://www.nber.org/papers/w8938 \\ NATIONAL BUREAU OF ECONOMIC RESEARCH \\ 1050 Massachusetts Avenue \\ Cambridge, MA 02138 \\ May 2002
}

This paper was presented at the April meeting of the Brookings Panel on Economic Activity. I am grateful for helpful suggestions from Ray Fair, George Hall, Ken Petrick, and members of the Panel. The views expressed herein are those of the author and not necessarily those of the National Bureau of Economic Research.

(C) 2002 by William D. Nordhaus. All rights reserved. Short sections of text, not to exceed two paragraphs, may be quoted without explicit permission provided that full credit, including (C) notice, is given to the source. 
The Mildest Recession: Output, Profits, and Stock Prices as the U.S.

Emerges from the 2001 Recession

William D. Nordhaus

NBER Working Paper No. 8938

May 2002

JEL No. E3, E5

\begin{abstract}
This paper examines the state of the United States economy as it emerges from the 2001 recession. A comparison of several central economic variables indicates that the 2001 recession was the mildest recession in the postwar period. In light of highly differentiated characteristics of recessions, the paper suggests that we differentiate among downturns by a five-category "recession severity scale," analogous to the Saffir-Simpson Hurricane Scale. According to this approach, the 2001 recession fits in the least severe box, a "category I recession," along with the 1963 and 1967 non-recessions. The paper next examines the behavior of profits in recent years and shows that financial finagling has infected the aggregate profits numbers. Finally, the study constructs a measure of the forward-looking return on equities and concludes that the prospective real yield on equities in early 2002 is at its low point of the last half-century.
\end{abstract}

William D. Nordhaus

Department of Economics

Yale University

28 Hillhouse Avenue

Box 208264

New Haven, CT 06520-8264

and NBER

william.nordhaus@yale.edu 


\title{
The Mildest Recession: \\ Output, Profits, and Stock Prices as the U.S. \\ Emerges from the 2001 Recession
}

\author{
William D. Nordhaus ${ }^{1}$ \\ Yale University
}

April 15, 2002

As of April 2002, the signs of economic recovery are sprouting like spring flowers. The U.S. has emerged from the short but painful winter that followed the asset-bubble burst in early 2000 and the anxiety following the events of 9/11 and the anthrax scare in the fall of 2001.

This report addresses the current state of the economy. What were the salient characteristics of the recession? What is the current state of the economy? How does the latest business cycle compare with earlier cycles? What are the initial conditions and therefore the prospects for recovery? What are the conditions of profits and equity markets? It is clearly too early to write the definitive economic history of the recent downturn, but it will be useful to describe the terrain as it appears in early 2002.

\footnotetext{
${ }^{1}$ This paper was presented at the April meeting of the Brookings Panel on Economic Activity. I am grateful for helpful suggestions from Ray Fair, George Hall, Ken Petrick, and members of the Panel.
} 


\section{1: The mildest recession}

To begin with, it appears that the 2001 recession was extremely mild. Real GDP barely declined in late 2001, and unemployment rose relatively little. Was it really a recession? For that matter, what is a recession?

From the point of view of economic welfare, business downturns are undesirable and therefore the subject of concern and study because they reduce the nation's output below its potential, reduce people's real incomes, and cause the economic pain of involuntary unemployment. The NBER defines a recession as a period with "a significant decline in activity spread across the economy, lasting more than a few months, visible in industrial production, employment, real income, and wholesale-retail sales." 2 Technically, a recession or contraction is a period of declining economic activity because it refers to the slope of the economy's trajectory rather than its level relative to a high-employment benchmark. From an economic point of view, however, the levels of output, unemployment, and employment relative to a high-employment baseline are probably more important than their derivatives.

To gauge the severity of the 2001 recession as compared to earlier ones, I first examine some of the fundamental variables involved in business cycles. Figure 1 shows a measure of business conditions that is designed to capture substantial declines in output. It shows an index that is zero if the economy is growing and equals the two-quarter growth rate of real GDP if that term is negative. The shaded areas are the NBER contractions (recessions). This measure is an accurate predictor of NBER recessions in that it calls every NBER recession but has no false positives.

\footnotetext{
2 From the NBER Business Cycle Dating Committee, March 11, 2002 at http://www.nber.org/cycles/recessions.html.
} 
The latest recession barely sneaks in the door, however. The negative growth for 2001 is barely visible and is by a wide margin the smallest downward spike of any recession.

A closely related index of cyclical conditions is total non-farm employment. If we construct a series on two-quarter growth rates like that in Figure 1, periods in which employment has declined are also good predictors of NBER recessions. Job loss was substantial, but the index has a very similar pattern as that in Figure 1, with the 2001 recession showing a tie with 1970for the smallest postwar decline. [Note to Editors: The graph seemed to add little, so I did not include it.]

Figure 2 shows an analogous measure for the unemployment rate. Here, the lines show four-quarter unemployment-rate increases when positive and zero when unemployment is falling; recessions are shown as shaded areas. In this dimension, there are several false positives indicating that the unemployment rate is a less reliable indicator than real GDP. A slight modification would hold that when the four-quarter change in the unemployment rate is greater than 1 percentage point, we have a reliable indicator of recession. By the unemploymentrate standard, the last two recessions are the mildest in postwar history.

A final indicator of business cycles is the "output gap," which measures the percentage difference between potential and actual GDP. The analysis of gaps is controversial because of the difficulties in defining and measuring potential output. Some classical approaches hold that output is essentially always equal to its potential, so output gaps are either definitionally zero or quickly disappear. Among schools that believe in gaps, some have measured gaps by interpolating between output peaks. Others measure gaps by using Okun's Law and calculating the output difference that is implicit between actual output and the output that would be consistent with a benchmark unemployment rate such as the NAIRU; this 
in turn gives rise to other ambiguities about whether the NAIRU is a wage or price NAIRU and to empirical difficulties in measuring the NAIRU.

For present purposes, I use a NAIRU-based measure of potential output based on estimates of potential GDP from the Congressional Budget Office (CBO). ${ }^{3}$ Figure 3 shows the output gap (again, only if positive) over the postwar period. This measure is particularly instructive because the gap measures the level of economic distress, whereas both Figures 1 and 2 measure the rate of change of output or unemployment. Here again, the 2001 recession is barely visible. It pales in size relative to the major downturns associated with the two oil shocks in 1974-78 and 1980-85. By the third test, 2001 was again the mildest recession in the postwar period.

\section{1: The highest trough}

A second unusual feature of the 2001 recession was that the level of output was relatively high as the economy emerged from recession. In other words, at the point where the economy reached its trough, which I assume was the fourth quarter of 2002, the gap between actual output and potential output was relatively small.

Figure 4 shows the estimated GDP gap at the trough of each postwar NBER recession (assuming that the trough came in the fourth quarter of 2001). The results are striking. The trough of the 2001 recession was as close to potential output as any postwar recession; only the 1954 recession showed as low a gap. Indeed to a first approximation, the economy was at its potential at the trough of the recession. This striking fact reflects two facets of the most recent recession: First, it was very mild with only a small decline in output (as shown in Figure 1), and, second, it 
started from a peak that had extremely high output and low unemployment for a peacetime period. This point can be expressed in a different way by noting that the unemployment rate in the fourth quarter of 2001 was 5.6 percent, which was close to most estimates of the current NAIRU, which cluster around 5-1/2 percent.

The high rate of utilization is not, however, shown by the Federal Reserve Board index of capacity utilization. The industrial production capacity utilization rate at the end of 2001 was close to the average for a recession trough. It should be recalled, however, that industrial production refers to only a small slice of the economy - approximately 20 percent of GDP - and that this slice is largely tradable goods for which domestic capacity utilization is increasingly irrelevant (oil production being the most obvious example). The most important limit on capacity is likely to be labor rather than manufacturing capital, so the low rate of capacity utilization is little comfort for those who worry about inflationary risks that would be encountered were a defense-spending-led recovery to be brisk over the next few years.

\section{Is it time to rethink the definition of recessions?}

By NBER business-cycle standards, 2001 is in the same category as 1933 or 1982. This discussion might well lead one to conclude that the traditional NBER business cycle methodology, which identifies only peaks and troughs without reference to the depth or severity of the downturn, is outdated. This approach was reasonable given the meager and incomplete data available when the businesscycle dating approach was invented by Mitchell and Burns. ${ }^{4}$ However, in light of

\footnotetext{
${ }^{3}$ I revised downward the estimated growth of potential GDP in the 1996-2001 period to 3.4 percent per year to reflect the most recent CBO estimates.

4 See particularly Wesley Clair Mitchell, Business Cycles, Berkeley, University of California Press, 1913 as the beginning of the business-cycle dating tradition. The most systematic study
} 
the plentiful, timely, and comprehensive data available today, we can do better than simply flying green flags or red flags depending upon the slope of the underlying economic indicators. In this, I am reminded of Tjalling Koopmans critique of Burns and Mitchell more than a half-century ago: "[E]ven for the purpose of systematic and large scale observation of such a many-sided phenomenon [as business cycles], theoretical preconceptions about its nature cannot be dispensed with, and the authors do so only to the detriment of the analysis." ${ }^{5}$

An alternative approach would be to develop quantitative criteria and categorize business downturns into the economic analog of the Saffir-Simpson Hurricane Scale. This suggestion in part reflects the finding that the volatility of output, along with the frequency and severity of business cycles, is declining in the United States. ${ }^{6}$ It also is based on the view that business cycles are more like hurricanes than pregnancies ${ }^{7}$ in that they are extremely diverse in their shape, size, and duration. It is in part motivated by the view that business-cycle dynamics are

was Wesley Clair Mitchell and Arthur F. Burns, Measuring Business Cycles, New York, National Bureau of Economic Research, 1946.

5 Tjalling C. Koopmans, "Measurement Without Theory," Review of Economics and Statistics, vol. 29, 1947, pp. 161-172.

6 See Olivier Blanchard with John Simon, "The Long and Large Decline in U.S. Output Volatility," Brookings Papers on Economic Activity, 2001:1.

7 The pregnancy or two-state view is associated with James Hamilton, "Analysis of Time Series Subject to Changes in Regime," Journal of Econometrics, 1990, vol. 45, pp. 39-70. A look at Figures 1 through 3, or a more systematic examination of the transition matrix between different states of the economy, would quickly reject the view that all recessions are a single state. 
often grounded in local instabilities in economies that can grow into full-scale disturbances if they are unchecked or trigger yet further instabilities.

As a start, I would propose categorizing recessions according a scale of I (pause in economic activity) to category $\mathrm{V}$ (severe depression). Based on the size and duration of the declines in growth rates and gaps in output, employment, and unemployment, I would tentatively classify recessions as follows:

Category I (pause in economic activity)

Category II (mild downturn)

Category III (typical recession)

Category IV (deep and prolonged recession)

Category V (depression)
$1963,1967,2001 ?$

1961,1970

$1949,1954,1958,1975,1991$

$1980 / 82$

1930s

Based on current data and prospects, the 2001 recession is by far the mildest of the postwar recessions.

This "new view" of business cycle as heterogeneous in duration and severity would also allow us to view periods of recovery as highly differentiated. In the present recovery, which probably started in late 2001, there is little room for the economy to expand before it hits the inflationary danger zone. As a result, monetary policymakers are likely to hit the brakes sooner and harder than they did in earlier recoveries. And the stimulus package passed in March 2002 will be the latest exhibit in the argument that fiscal policies are generally implemented too much, too late, and with the wrong sign. 


\section{Deciphering the profits numbers}

I turn next to a discussion of the condition of profits and equity markets. Part of the exhilaration of the 1990s was due to the rapid growth in corporate earnings. For the period 1992-2000, profits from the National Income and Product Accounts (NIPA) grew at an average rate of 8 percent per year. Over the same period, Standard and Poor earnings per share grew at 15 percent per year.

Before digging into the concepts and numbers, it must be recognized that "profits" are a most elusive concept. There are at least four important definitions profits for accounting purposes, profits for tax purposes, profits as measured in the NIPA, and economic profits. The first three are widely discussed, while the fourth is usually ignored. From the point of view of the corporation (rather than its shareholders), a reasonable definition of economic profits would be distributions to shareholders plus the change in real net worth from one period to the next. Such a definition differs from the other three measures of profits in important ways. Relative to economic profits, NIPA profits exclude real asset appreciation; accounting profits have many inappropriate concepts, of which the treatment of depreciation and capital appreciation are two; while both tax and accounting profits treat capital gains in an inappropriate manner by excluding some accrued gains and including gains that are only due to price level changes.

In practice, the only two available comprehensive measures of profits are NIPA and S\&P profits. "NIPA profits after taxes" exclude the IVA and CCA (inventory valuation adjustment and capital consumption adjustment), while "NIPA adjusted profits after taxes" include the IVA and CCA. There are two versions of S\&P earnings. The first is operating earnings, which exclude the impact of cumulative accounting changes, discontinued operations, extraordinary items, and special items; the second is "as reported," which include these items. In 
addition, there are two important NIPA concepts. The earnings used in priceearnings ratios are the reported variant.

Although S\&P and NIPA profits are often compared, they actually have substantial differences in definitions, methodologies, source data, and coverage. ${ }^{8}$ I will highlight some of the major differences. First, the S\&P covers only 500 large corporations, while the NIPA covers the entire economy, including small (subchapter S) corporations. Second, the NIPA is designed to measure the income from current production earned by domestic corporations, while S\&P earnings are measured on a financial-accounting basis. The third major difference between NIPA and S\&P earnings is that the former excludes capital gains, which can be substantial; in 1998, for example, corporations reported \$205 billion of capital gains in the profits. Fourth, the $S \& P$ is a changing panel of firms, which requires a complicated chaining procedure that ensures comparability of market value over time but does not ensure comparability of earnings. ${ }^{9}$

The fifth difference is seen in the capital consumption adjustment (CCA) and inventory valuation adjustments (IVA), which measure the difference between economic cost and accounting cost. While these components are generally quite

8 A full discussion is contained in Kenneth Petrick, "Comparing NIPA Profits with S\&P Profits," Survey of Current Business, April 2001, pp. 16-20.

${ }^{9}$ When firms enter and leave the S\&P 500, continuity of the share-price index is achieved by creating a total market "divisor" to link different periods together. If the price-earnings ratios of entering and leaving firms are unequal, this will induce a change in the price-earnings ratio of the aggregate. The procedure is discussed at http://www.spglobal.com/5sec3.pdf.

An examination of the divisor suggests that firm substitutions are substantial. The divisor rises when new firms enter with higher value than exiting firms, when companies issue new shares, or when two S\&P companies merge. The size of the divisor has grown by about 4 percent per year in the last decade, but there is no empirical evidence on the reasons for this growth. 
smooth, the CCA in the fourth quarter of 2001 jumped from $\$ 13$ billion to $\$ 186$ billion and led to a huge difference between adjusted NIPA profits and S\&P earnings. A sixth difference is source data, where the NIPA are in principle derived from tax accounts while the S\&P data are derived from financial accounts. On the other hand, early estimates of NIPA profits are based on financial-accounts data, and they are often revised, while S\&P never revise the data or take into account restatements of earnings.

Figure 5 shows four measures of post-tax corporate profits over the 1986-2001 period. The top two lines are NIPA corporate profits after taxes; the very top line is adjusted post-tax profits (which includes the adjustments), while the second line is unadjusted post-tax profits (which excludes the adjustments). The bottom two curves show the reported and operating post-tax earnings of the companies of the Standard and Poor 500. The top of the bottom two lines shows operating earnings, which are more or less the earnings from continuing operations. The bottom line shows earnings "as reported," and includes the extraordinary items (such as would occur when a company revalues operations, inventories, or acquisitions and takes this as a one-time charge).

The data for 2001:4 show divergent trends in the profits numbers. Post-tax adjusted NIPA profits increased 6 percent year-over-year, while the three other series declined by between 23 and 36 percent. The 2001:4 NIPA figures were affected by a one-time tax change, arising from the March 2002 stimulus package that allowed firms to expense 30 percent of covered investments. Because the source data for the NIPA is extremely sparse at this stage, it seems likely that the latest NIPA profits data will be significantly revised in the next few years.

All of the different series on profits have taken a major dive in the last few years. The share of the two NIPA post-tax profits series peaked in 1997 at around 7 percent of GDP; since that time their share has declined by about one-third, or by 
slightly more than 2 percentage points through the third quarter of 2001. The S\&P earnings share peaked three years later. The lag of S\&P earnings behind NIPA profits was not a feature of earlier cycles and has no obvious economic rationale.

What might have caused this most unusual pattern of earnings? The obvious suspicion is that the rapid rate of "innovation" in accounting techniques has distorted the timing of reported earnings over the last few years. Every day, the newspapers recount a host of new techniques by which companies bolster reported earnings. Some of the most egregious examples of Not Generally Accepted Accounting Principles, or NGAAP, include swapping capital assets such as naturalgas-futures contracts (Enron) or "dark" fiber-optic networks (Global Crossing, Qwest, Enron) and capitalizing the outflow while recognizing the inflow as current revenues; increasing the salvage value of trucks over time (Waste Management); recognizing the returns to pension plans as operating incomes (IBM); recording sales of products that were still in research (McKessonHBOC); changing the pattern of accounting revenues from rentals (Xerox); increasing the value of the unused capacity of landfills even as they fill up (Waste Management); reporting happy pro forma numbers when the reality is unpleasant (Amazon.com, Yahoo, and Qualcomm among a crowd of other dot.coms dead or alive); using funds set aside as merger and acquisition reserves to increase operating income (Cendant); and doubling earnings by simply neglecting to include expenses (BroadVision). ${ }^{10}$

Aside from enrichment of the few and depleted pension plans of the many, a major question is whether the prevalence of NGAAP is sufficiently large and pervasive to affect the aggregate numbers or to have macroeconomic significance. Figure 5 suggests that NGAAP earnings have indeed infected the total reported

\footnotetext{
${ }^{10}$ The report on the SEC's analysis of Waste Management's NGAAP were highlighted in The New York Times, March 28, 2002. A description of the swaps of "dark" fiber-optic capacity was described in The New York Times, March 27, 2002.
} 
S\&P earnings. It seems clear that the peak in S\&P earnings lagged behind the peak in NIPA earnings because companies were "managing" their earnings (in this context, preventing an accounting decline in earnings). However, they could only prevent the earnings decline for a couple of years, after which the they run out of gimmicks or accountants -- or analysts and the SEC begin to blow their faint whistles.

Another interesting feature of the recent profits data, again shown in Figure 5, is that reported profits are currently extremely low relative to operating profits. The difference between reported and operating profits is primarily one-time charges that companies take to correct for past business or accounting errors - as they hang out the dirty laundry, so to speak. The declining ratio of reported to operating profits in the last two years probably reflects the tendency of companies to purge their earnings and balance sheets of questionable elements in light of the Enron scandal. The size of the write-downs has become truly enormous in late 2001 and early 2002. Announced or estimated write-downs include \$54 billion for AOL TimeWarner, $\$ 20$ to $\$ 30$ billion for Qwest, $\$ 15$ to $\$ 20$ billion for WorldCom, $\$ 10$ billion for VeriSign, $\$ 4$ billion for Cisco, $\$ 4$ billion for AT\&T, and the list goes on. Analysts are bruiting around a total price tag of $\$ 1$ trillion for the Great Balance-Sheet Purge of 2002.11

In considering future earnings prospects, we must take into account both the cyclical depression of profits and the likelihood that reported profits are contaminated by an accounting purge. Figure 6 shows the historical trend in the ratio of quarterly S\&P (reported) earnings per share to GDP and unadjusted NIPA earnings to GDP, where both are scaled so that the average ratio over the 1948-2001 period equals 100. Again, NBER recessions are shown as shaded areas.

11 “Buying Binge Could Cost Corporate America \$1 Trillion," USA Today, April 5, 2002, p. 1B. 
The two series in Figure 6 move together during most of the period until 1990. Since 1990, the pattern looks quite different, with the NIPA numbers largely skirting the 1991 recession. The most dramatic difference comes at the end of the period with the huge drop in reported S\&P earnings, presumably due primarily to the balance-sheet purge.

To obtain a more realistic estimate earnings than reported S\&P earnings, I calculated a series on S\&P earnings corrected for the cycle and accounting purges, or "corrected S\&P earnings" for short. This series was calculated by taking a regression of the logarithm of S\&P reported earnings on the logarithm of unadjusted NIPA profits after taxes, time, a cyclical variable, and a constant. I then forecast corrected S\&P earnings by assuming that unadjusted NIPA profits are set at their cyclically adjusted level and that S\&P profits are at the level forecast on the basis of cyclically corrected NIPA profits. In effect, this uses NIPA profits as a proxy for cleaned-up S\&P reported earnings. I then forecast S\&P profits for the period 2001:4 through 2002:4. The projection assumes that real GDP grows one-half percentage point faster than potential output during 2002. This procedure along with recent and projected values of S\&P profits are described in more detail in Appendix A.

This experiment indicates that reported S\&P earnings were indeed depressed at the end of 2001 for a combination of cyclical and accounting reasons. Reported S\&P earnings for 2001 were about 30 percent below the estimate of corrected or "clean" S\&P earnings. If earnings were to rebound to their forecasted corrected levels at the end of 2002, they would be 55 percent higher than their levels in 2001:4.

In summary, there has been a substantial fall in profits since their peak in the late 1990s. The recent pattern of profits suggests that financial finagling has infected 
the reported profits figure in the last decade, particularly in the aggregate financialaccounting numbers. Perhaps the best summary would be to recall the wisdom in John Kenneth Galbraith's saying that depressions catch what the auditors missed.

\section{Party time continues in equity markets}

Robert Shiller argued in his influential and exquisitely timed book, Irrational Exuberance, that equity prices were seriously out of line with economic fundamentals. ${ }^{12}$ In Shiller's most recent analysis with John Campbell, the bears of academe write:

[W] believe that our original testimony and article are even more relevant today [March 2001]. Valuation ratios moved up in the year 2000 to levels that were absolutely unprecedented, and are still nearly as high as of this writing at the beginning of 2001. Even allowing for the possibility that the economy and financial markets have undergone some structural changes, these ratios imply a stronger case for a poor stock market outlook than has ever been seen before. ${ }^{13}$

What has changed since that time? The major developments since early 2001 have been the steep decline in earnings discussed in the last section along with a sideways movement of stock prices. To illuminate the Campbell-Shiller thesis, I have looked at the real return on equities and the yield spread between equities and safe assets.

12 Robert Shiller, Irrational Exuberance, Princeton University Press, Princeton, N.J., 2001.

${ }^{13}$ John Y. Campbell and Robert J. Shiller, "Valuation Ratios and the Long-Run Stock Market Outlook: An Update, “ March 2001, Cowles Foundation Discussion Paper No. 1295, p. 1. 
The basic assumption in this analysis is that the earnings-price ratio is a reasonable estimate of the forward-looking real return on equities. ${ }^{14}$ The "forwardlooking real return on equity" here means the expected total return per share (dividends plus capital gains) corrected for movements in the general price level.

The derivation of this result is presented in the technical Appendix B, but the reasoning can be described verbally. Begin with the market value of the firm, the assets of the firm, and the earnings or profits on assets. For this purpose, assets should include all tangible and intangible assets. $q$ is the ratio of the market value of the firm to its total assets, where marginal $q$ applies to new investments and average $q$ applies to old assets. It will simplify the discussion to assume that firms have no debt and to ignore taxes.

The conditions under which the prospective return on equity equals the earnings-price ratio are neither obvious nor obviously correct. To begin with, the theory needs to assume that earnings are an accurate measure of true profits, which definitely gets the theory off to a bad start. One simple case where the earning-price ratio is a good forward-looking estimate of the return on equities comes when (i) marginal $q$ equals 1 , (ii) the $q$ ratios are constant, and (iii) the expected rate of return on capital is constant. Some other cases are discussed in the Appendix B. In reality, the $q$ ratios and the expected return on capital are likely to bounce around a great deal, so the actual returns on equity will differ from the earnings-price ratio. In terms of market conditions in early 2002, the major reasons to believe that equity returns will differ from the earnings-price ratio are if the rate of profit rises because

\footnotetext{
${ }^{14}$ Other popular approaches sometimes compare the earnings-price ratio or the dividendprice ratio with nominal interest rates. These approaches make the fundamental error of confusing real and nominal magnitudes - in effect assuming that the prices of goods and dollar returns are constant.
} 
it is currently depressed or if average $q$ falls because assets are currently overvalued.

With these theoretical considerations behind us, Figure 7 shows two variants of the estimated real forward-looking return on equities over the post-war period. Variant 1 is the earnings-price ratio for the Standard and Poor 500 using quarterly earnings. ${ }^{15}$ Variant 2 takes variant 1 and performs the correction for the business cycle and for accounting problems discussed in the last section.

Both series tell the same story. The real yield on equities moved up and down during the postwar period and then declined continually since 1980. In 1980, the forward-looking yield was around 14 percent, and the actual return over the 19802001 period was 12 percent. The real yield on equities in 2001 was between 2 and 3 percent per year depending upon which measure is used. The real forward-looking return on equities in 2001 was by a wide margin at the lowest level of the entire postwar period.

While the real yield picture is interesting, a more fundamental question examines the difference between the real yield on equities and the riskfree (or a safe) real rate of interest. For this calculation, I took the riskfree real rate of interest to be the 10-year Treasury bond rate minus the four-quarter trailing rate of inflation for the chained price index for GDP. ${ }^{16}$ I call the difference between the real equity

\footnotetext{
15 The published measure of earnings in the S\&P numbers (such as the price-earnings ratio) uses a four-quarter trailing average of earnings. In the present analysis I take the ratio of the seasonally adjusted current quarterly earnings at an annual rate and divide this by the current period stock price index.
}

${ }^{16}$ Alternative approaches would use the price index for corporate product or the CPI rather than the chain price index for GDP to measure inflation, and alternative interest rates would be the real short-term interest rate or Treasury real interest bonds. These would change the levels of the curves but would not change the general trend. For example, over the last five 
rate and the real bond rate the "equity spread," but others might call it the equity premium. Standard doctrine holds that the equity spread should be positively associated with the systematic risk of equities and should definitely be positive.

Figure 8 shows two different calculations of the equity spread over the last half century using the two series on the forward-looking return to equities from Figure 7. The story here is slightly different from that in Figure 7. The spread on equities declined sharply in the early 1980s with the high real interest rates of that period. The spread was between 2 and 4 percent in the late 1980s, and it has gradually declined since that point. At the end of 2001, the equity spread was close to zero -- either slightly negative if the uncorrected earnings figure is used or slightly positive if the corrected figure is used.

Looking at the most recent data, and focusing on the corrected figures ( $\mathrm{r} 2$ and s2), the spread has moved up slightly since the peak of the equities market in the spring of 2000. In 2000:1, the spread between equities and bonds was minus 160 basis points, while by the end of 2004 the spread had moved to positive 47 basis points. For the latest period (mid-April 2002), bond yields had risen and the corrected equity spread had dipped back down to minus 30 basis points. ${ }^{17}$

decades, the real one-year Treasury rate averaged about 70 basis points less than the 10-year rate, so the spread would be that much higher over the period. The average rate of inflation for the GDP price index was 30 basis points lower than that of the CPI for the last five decades. The suggests that the estimated returns or spreads might differ by as much as 100 basis points per year if different indexes were employed.

${ }^{17}$ The changing spread could arise from many factors. Changes in risk aversion, changing expectations of the real growth in the returns on equities, and changing perceived riskiness of stocks are the fundamental economic factors (as distinguished from technical or psychological factors). Is seems hard to derive sound reasons why any of the three fundamental factors have changed so dramatically in favor of equities in recent years. It has been argued that the equity premium was excessive during most of the twentieth century, 
It is useful to compare these estimates with surveys on what financial analysts actually believe. According to Welch's survey of 510 economics and finance professors conducted in August 2001, the average equity spread was estimated to be 3.4 percent for a one-year horizon and 4.7 percent on a 30-year horizon. ${ }^{18}$ About 6 percent believed that the equity premium would be negative at a one-year horizon and none believed that it would be negative at a 30-year horizon. Clearly, neither Campbell and Shiller, Shiller, or earning-price ratios make much of a dent in the optimism of finance professors.

The overall results suggest that the prospective yield on equities is about equal to that on safe assets. At the same time, the prospective real yield on equities is at its low point of the last half-century. The overvaluation of equities has improved slightly since Campbell and Schiller's last gloomy prognostication, but it hardly looks rosy.

\section{Summary}

The basic description of the current recovery is clear. The downturn of 2001 was extremely mild, somewhere between a category I and category II recession on the economic hurricane scale. Because the economy began the recession at a usually high peak and because the downturn was short and mild, the economy at the

but no theory would predict a zero equity premium. Nor does it seem plausible that a model with constant equity premium fits recent experience.

18 Ivo Welch, "The Equity Premium Consensus Forecast Revisited," Cowles Foundation Discussion Paper, no. 1325, September 2001. The survey question was: "I expect the average equity premium (i.e., expected return on the market net of the short-term interest rates) over the next 1 year to be..." The market was taken to be the S\&P 500 . 
trough of the recession (assumed to be in late 2001) was close to full employment in terms of inflationary pressures.

Looking at financial markets, profits are depressed relative to their peaks in the 1990s, and the forward-looking real return on equities is about equal to the riskfree real rate of interest on medium-term U.S. government bonds. For those who make their living in financial markets, this is not good news. Bonds are likely to get hit quickly if the economy recovers sharply and the Federal Reserve follows its script of preempting inflationary output growth. Stocks are still overvalued relative to most of the postwar period -- with significant prospects of financial tightening and growing concern about what bad news still hides inside the black box of earnings statements. It seems unlikely that the United States will soon return to the bubbly days of the late 1990s. 


\section{Appendix A. Derivation of corrected S\&P earnings}

S\&P reported profits are affected by both the business cycle and by accounting fraud and low misdemeanors. To estimate a series on “clean" or corrected S\&P profits, I use NIPA profits as a proxy variable. In what follows, $\mathrm{P}_{\mathrm{t}}$ is measured S\&P profits, $\mathrm{P}_{\mathrm{t}}{ }^{*}$ is true $\mathrm{S} \& \mathrm{P}$ profits, $\mathrm{P}_{\mathrm{t}}{ }^{* \mathrm{CC}}$ is true cyclically corrected S\&P profits. $\mathrm{NP}_{\mathrm{t}}$ and $\mathrm{NP}_{\mathrm{t}} \mathrm{CC}$ are NIPA unadjusted profits with and without a cyclical correction, respectively. The superscript "CC" indicates that the variable is cyclically corrected so that it equals its estimated value at potential output.

The first step is to obtain cyclically corrected unadjusted NIPA profits after taxes. This is obtained by estimating the following equation from 1948:1 to 2001:4.

$$
\mathrm{NP}_{\mathrm{t}} / \mathrm{GDP}_{\mathrm{t}}=\mathrm{a}_{0}+\mathrm{a}_{1} \text { Time }+\mathrm{a}_{2}\left(\mathrm{U}_{\mathrm{t}}-\mathrm{NAIRU}_{\mathrm{t}}\right)+\mathrm{e}_{1 \mathrm{t}}
$$

I then measure cyclically adjusted profits by removing the cyclical influence:

$$
\mathrm{NP}_{\mathrm{t}} \mathrm{CC}=\mathrm{GDP}_{\mathrm{t}}\left[\mathrm{NP}_{\mathrm{t}} / \mathrm{GDP}_{\mathrm{t}}-\mathrm{a}_{2}\left(\mathrm{U}_{\mathrm{t}}-\mathrm{NAIRU}_{\mathrm{t}}\right)\right]
$$

Next, estimate S\&P profits as a function of NIPA profits and a cyclical variable.

$$
\ln \left(P_{t}\right)=b_{0}+b_{1} \ln \left(N_{t}\right)+b_{2} \text { Time }+b_{3}\left(U_{t}-N A I R U_{t}\right)+e_{2 t}
$$


Adjusted S\&P profits are then determined by using the forecast from this equation with NIPA profits at their cyclically corrected levels:

$$
\ln \left(\mathrm{P}_{\mathrm{t}}{ }^{* \mathrm{CC}}\right)=\mathrm{b}_{0}+\mathrm{b}_{1} \ln \left(\mathrm{NP}_{\mathrm{t}} \mathrm{CC}\right)+\mathrm{b}_{2} \text { Time }
$$

Recent values of reported and adjusted S\&P earnings per share are the following:

\begin{tabular}{|c|c|c|c|}
\hline Period & Actual & Adjusted & Actual/Adjusted (percent) \\
\hline 1999:Q1 & 10.72 & 9.02 & 118.9 \\
\hline 1999:Q2 & 12.23 & 9.06 & 135.1 \\
\hline 1999:Q3 & 12.39 & 9.10 & 136.1 \\
\hline 1999:Q4 & 12.86 & 9.65 & 133.2 \\
\hline 2000:Q1 & 13.43 & 9.78 & 137.4 \\
\hline 2000:Q2 & 13.18 & 9.97 & 132.2 \\
\hline 2000:Q3 & 14.24 & 10.00 & 142.4 \\
\hline 2000:Q4 & 9.13 & 9.73 & 93.8 \\
\hline 2001:Q1 & 8.97 & 9.23 & 97.3 \\
\hline 2001:Q2 & 4.72 & 9.20 & 51.3 \\
\hline 2001:Q3 & 5.43 & 8.83 & 61.5 \\
\hline 2001:Q4 & 5.70 & 8.40 & 67.8 \\
\hline 2002:Q1 & & 8.50 & \\
\hline 2002:Q2 & & 8.61 & \\
\hline 2002:Q3 & & 8.71 & \\
\hline 2002:Q4 & & 8.82 & \\
\hline
\end{tabular}

Appendix B. Relationship of earnings-price ratio to prospective real return on equities

This section derives the statements in the paper concerning the relationship between the forward-looking real return on equities $\left(r^{\mathcal{e}}\right)$ and the earning-price ratio $(e / p)$. 
Assume that $q^{A}$ is average $q, q^{M}$ is marginal $q$, the price per share is $p$, total assets per share are $k$, earnings are $r^{k}$ per unit of asset per year, $r^{e}$ is the total return on equities per year, and $d$ is the dividend-payout ratio. Further assume that there are no bonds and no taxes. We consider the value of the variables in periods $t$ and $t+1$.

To begin with, the earnings-price ratio in the first period is equal to the ratio of the return on assets to average $q$ :

$$
e_{t} / p_{t}=r k_{t} k_{t} / q A_{t} k_{t}=r^{k_{t}} / q^{A}
$$

To derive the total return on equities, note that the price per share in the first period is $p_{t}=k_{t} q^{A} t$. Reinvested earnings are $\left(1-d_{t}\right) r_{t} k_{t}$, so the price per share in the second period is

$$
p_{t+1}=k_{t} q_{t+1}+\left(1-d_{t}\right) r_{t} k_{t} q M_{t+1}
$$

The total return on equities between the first and second period is then

$$
\begin{array}{r}
r_{t+1}=\left[d_{t} r k_{t} k_{t}+k_{t} q A_{t+1}+\left(1-d_{t}\right) r k_{t} k_{t} q M_{t+1}\right] / k_{t} A_{t-1} \\
=\left(q A_{t+1} / q A_{t}\right)+\left[d_{t} r k_{t}+\left(1-d_{t}\right) r k_{t} q M_{t+1}\right] / q A_{t}-1
\end{array}
$$

One polar case is where marginal $q$ is one even though average $q$ is greater than one. This case would apply when the firm has supernormal profits in one area (say, on a patent or a piece of software) but is unable to leverage the market power into other markets. In this case, as long as average $\mathrm{q}$ is constant, $r^{e}=r^{k} / q^{A}=e / p$. That is, the return on equities is the rate of return on existing assets divided by 
average $q$, which is the earnings-price ratio. This case is interesting because the return on equities diverges from the return on capital.

An alternative view would come when marginal $q$ is different from one. This case might apply for a firm that has been able to extend its monopoly into other markets. In this case, $r e=e / p$ when $d=1$, or where all earnings are paid out as dividends.

We can use numerical values to determine the forward-looking return for other cases. For large corporations, assume that the rate of return on assets is 8 percent per year after tax, average $q$ is 1.6 , and the dividend-payout ratio is 0.5 . Suppose that the marginal $q$ is 1.3 , which would imply that firms could project some but not all of their market power into new investments. Applying equation (3) yields a forward-looking return of 5.8 percent per year, which is higher than the $e / p$ ratio of 5 percent.

As a final case, assume that $q$ deviates from unity because of speculative bubbles or anti-bubbles, and that average $q$ regresses back toward 1 with a decay rate of ten percent per year [i.e., on average $q$ moves 10 percent of the way from ( $q$ 1) to 1 each year]. Then, using the same numbers as in the last paragraph, the forward-looking real return on equities would be 2 percent per year rather than 5.8 percent per year, and in this case is below the earnings-price ratio.

The main point is that the forward-looking return on equities generally involves both average and marginal $q$. And where average $q$ is very high, the forward-looking return can be well below the rate of return on capital, $r$. 


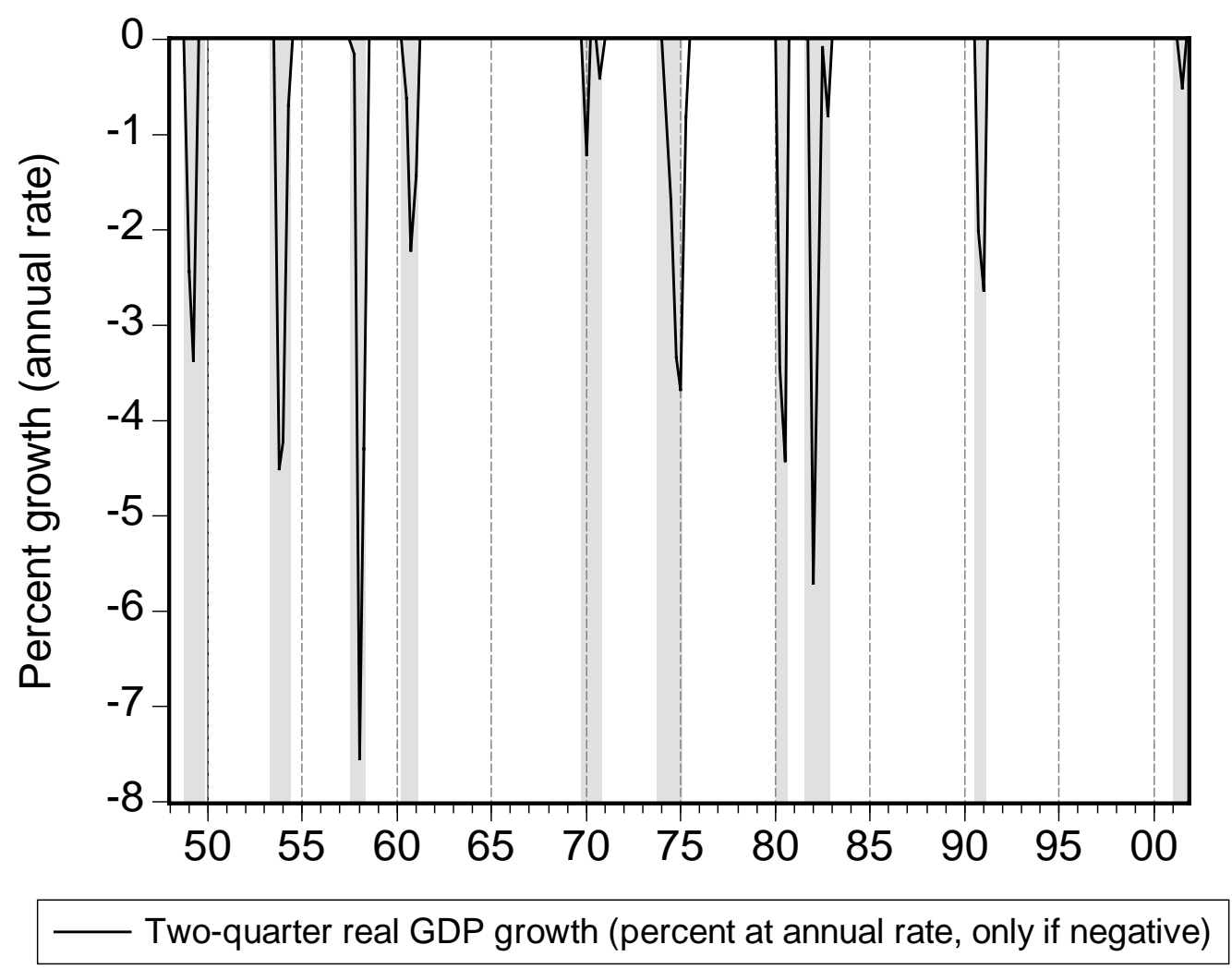

Figure 1. Recessions and Real GDP Growth

The line shows the two-quarter growth rate in real GDP if that is negative and zero otherwise. The shaded regions are the NBER contractions. Most macroeconomic data are from DRI's macroeconomics database, with updates for the latest data from the web pages of the relevant government statistical agency. GDP data are through March 28, 2002. 


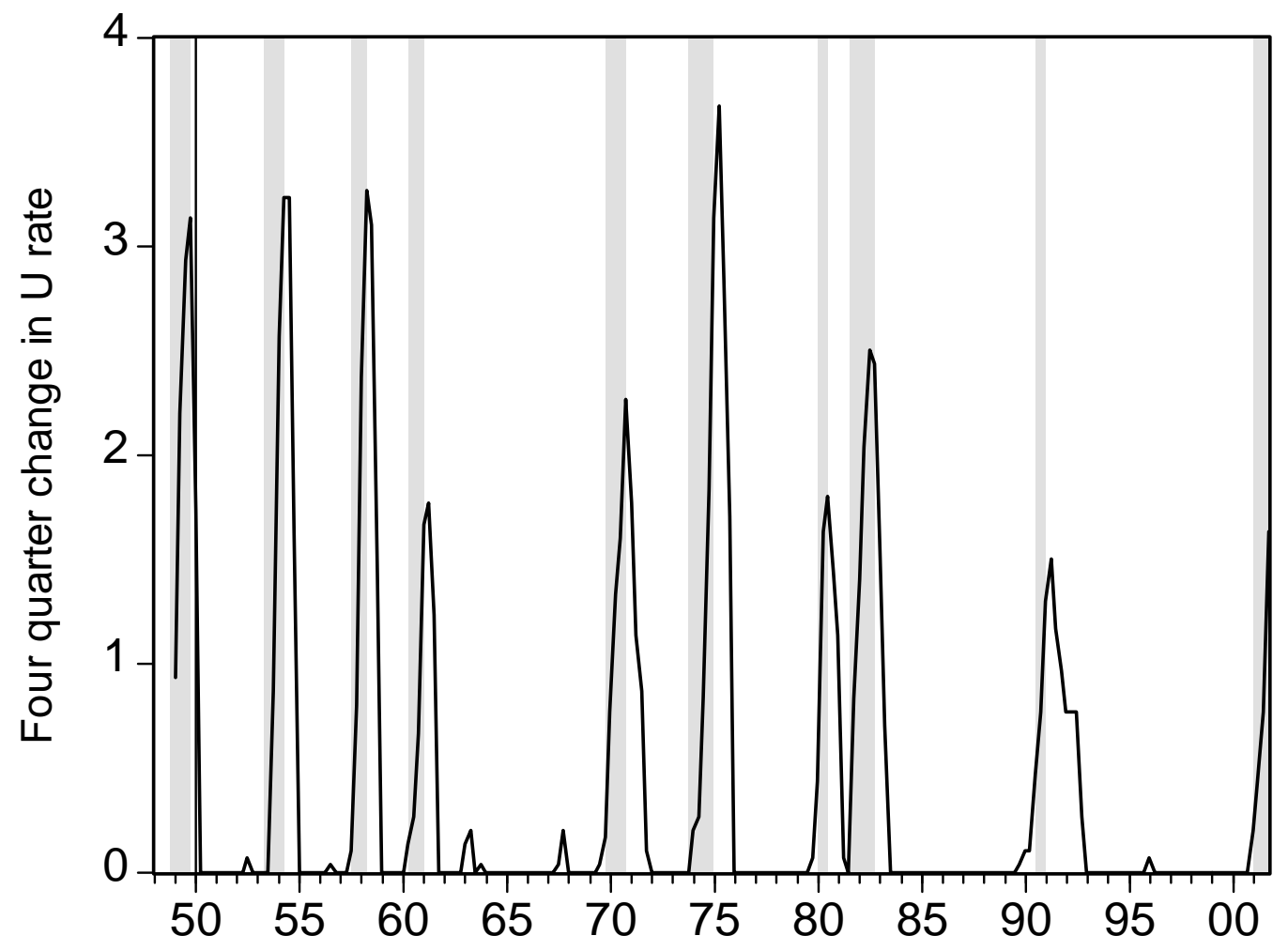

Figure 2. Increase in unemployment and recessions

This figure shows the four-quarter increase in the unemployment rate if positive, zero otherwise. 


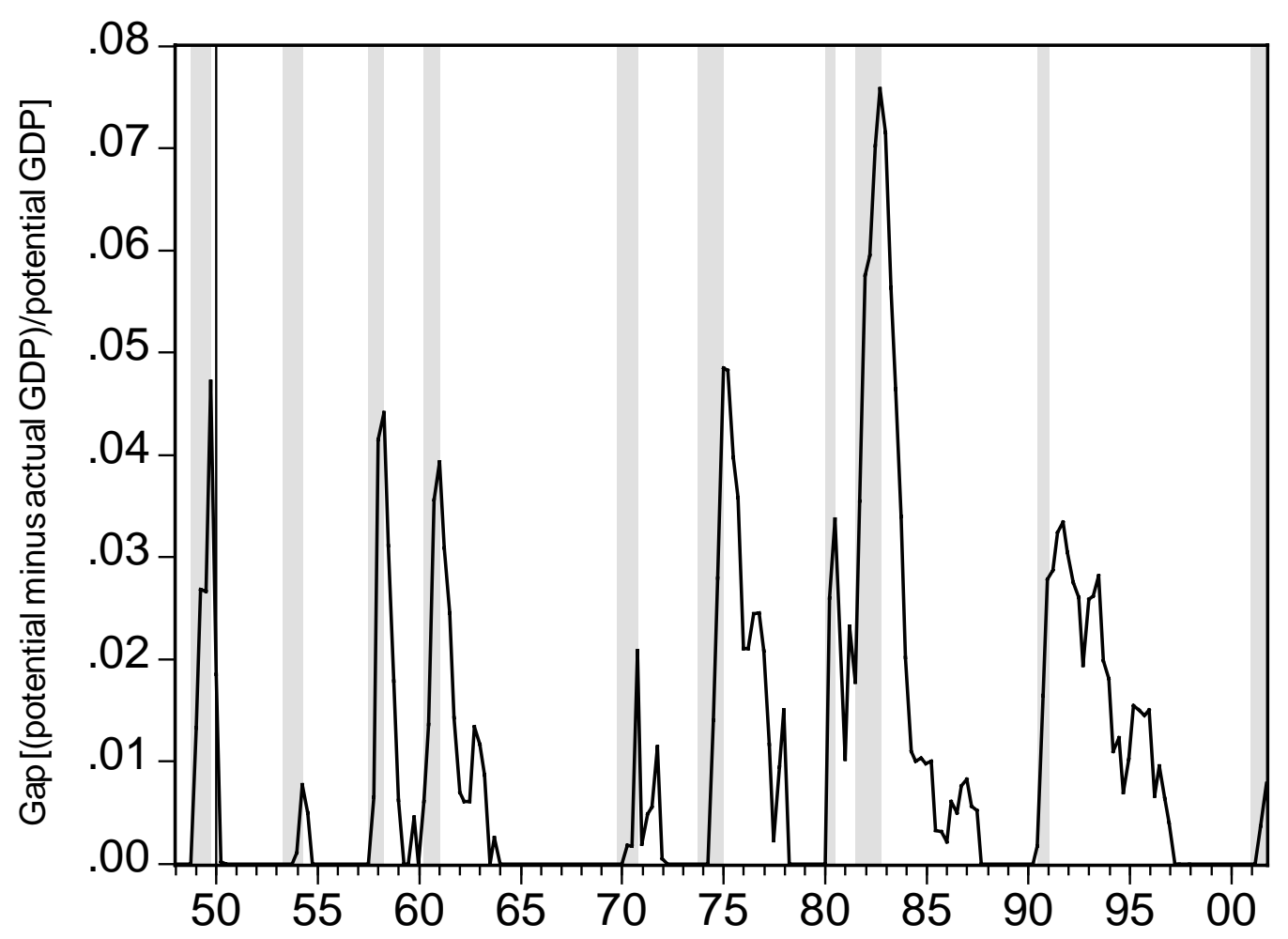

Figure 3. Output Gaps in the Postwar Period

The output gap measures the difference between potential or fullemployment output and actual output. For this graph we have set negative gaps (where output is above potential) equal to zero. The gap is calculated using potential output from the Congressional Budget Office. (Source: CBO's Method for Estimating Potential Output: An Update," August 2001, available at http://www.cbo.gov/ .) 


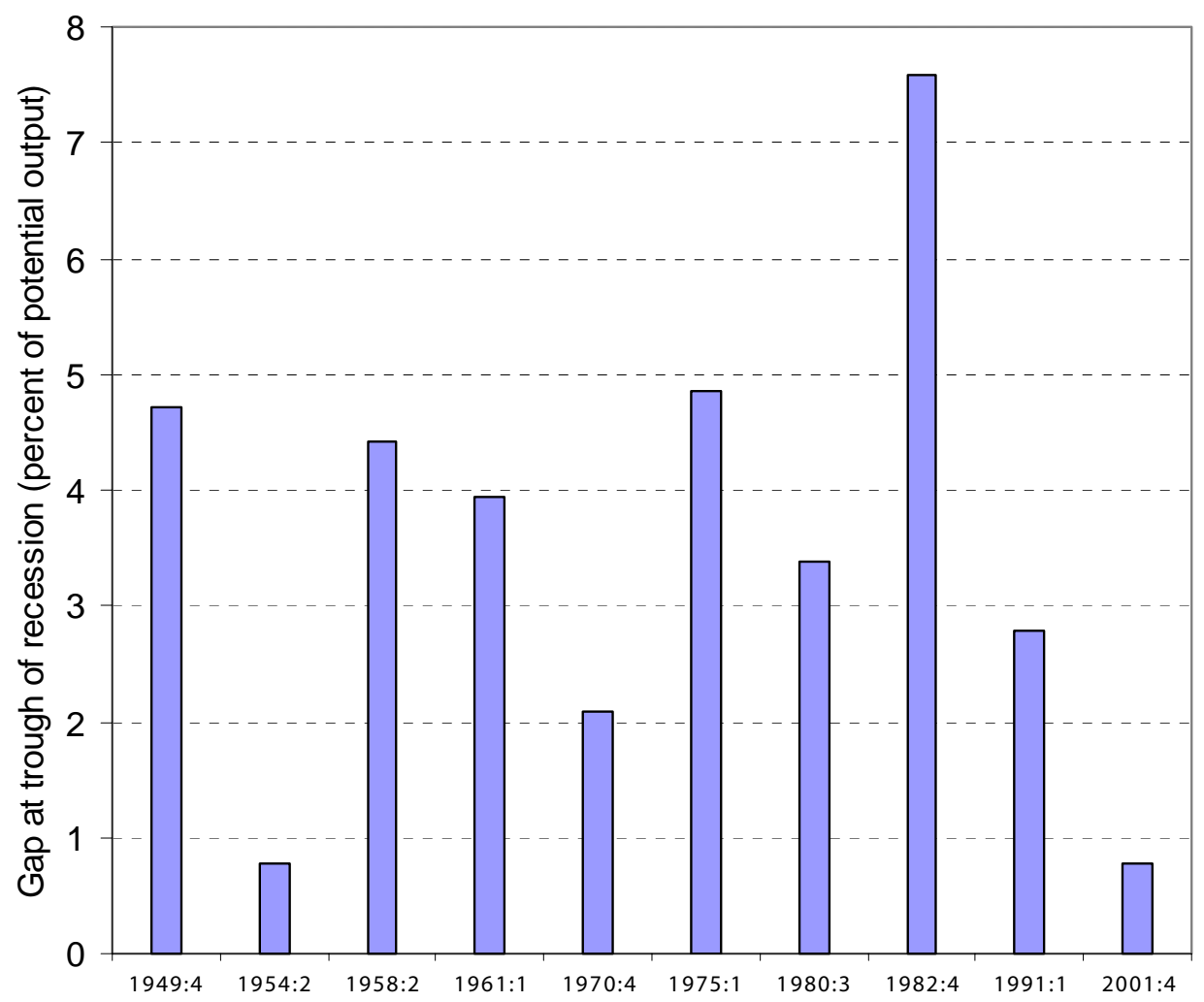

Figure 4. Gap at Trough of Recession for Ten Postwar

\section{Recessions}

The bars show the output gap at the troughs of the ten postwar recessions. The gap is calculated as the ratio of (CBO potential real GDP - real GDP)/(CBO potential real GDP). The source for potential output is given in Figure 3. 


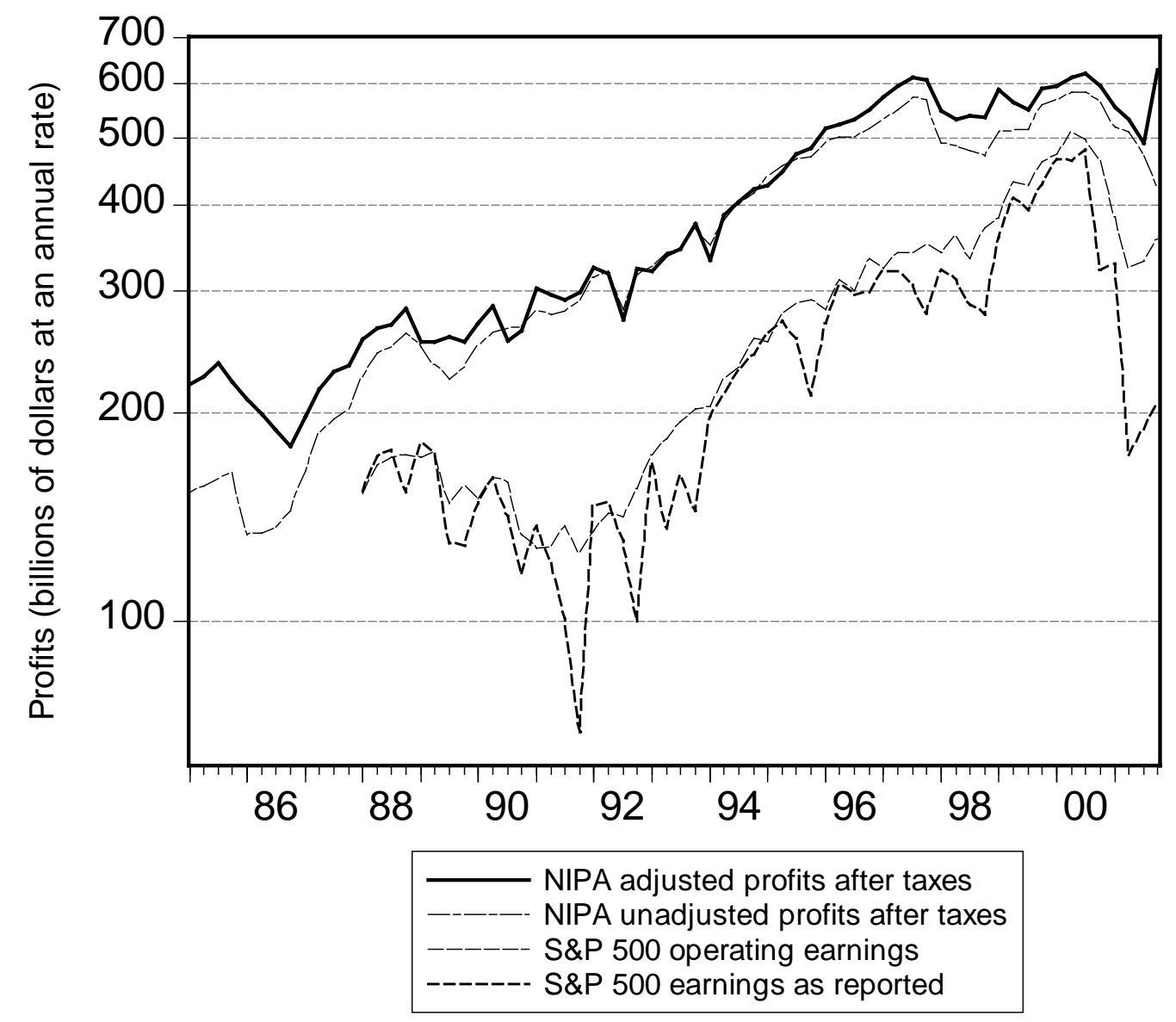

Figure 5. Alternative Versions of After-Tax Corporate Profits, 1985-2001

NIPA profits are total corporate profits after tax from the national income and product accounts with and without IVA and CCA. S\&P earnings are total profits of companies in the S\&P 500. See the text for a discussion of the conceptual differences among the series. Data on S\&P profits were taken from the web page of Standard and Poor at http://www.spglobal.com/earnings.html . 


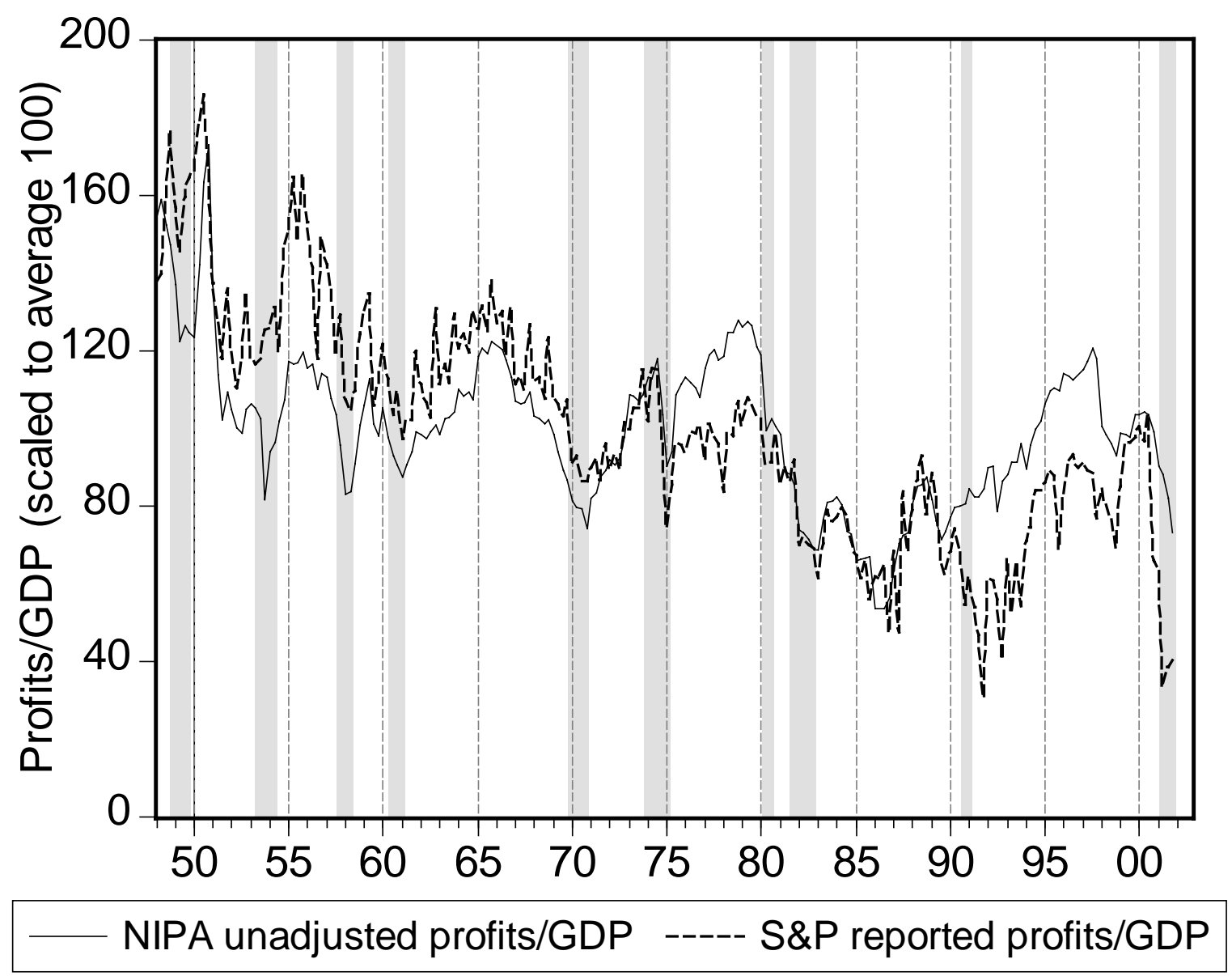

Figure 6. Trends in NIPA and S\&P Profits Relative to GDP, 1948-2001

This figure shows the trend and cyclical pattern of the ratio of unadjusted NIPA profits after taxes (without IVA or CCA) and S\&P reported earnings per share. Both are divided by nominal GDP and scaled so that the average of the series is 100 over the period 1949 to 2001. 


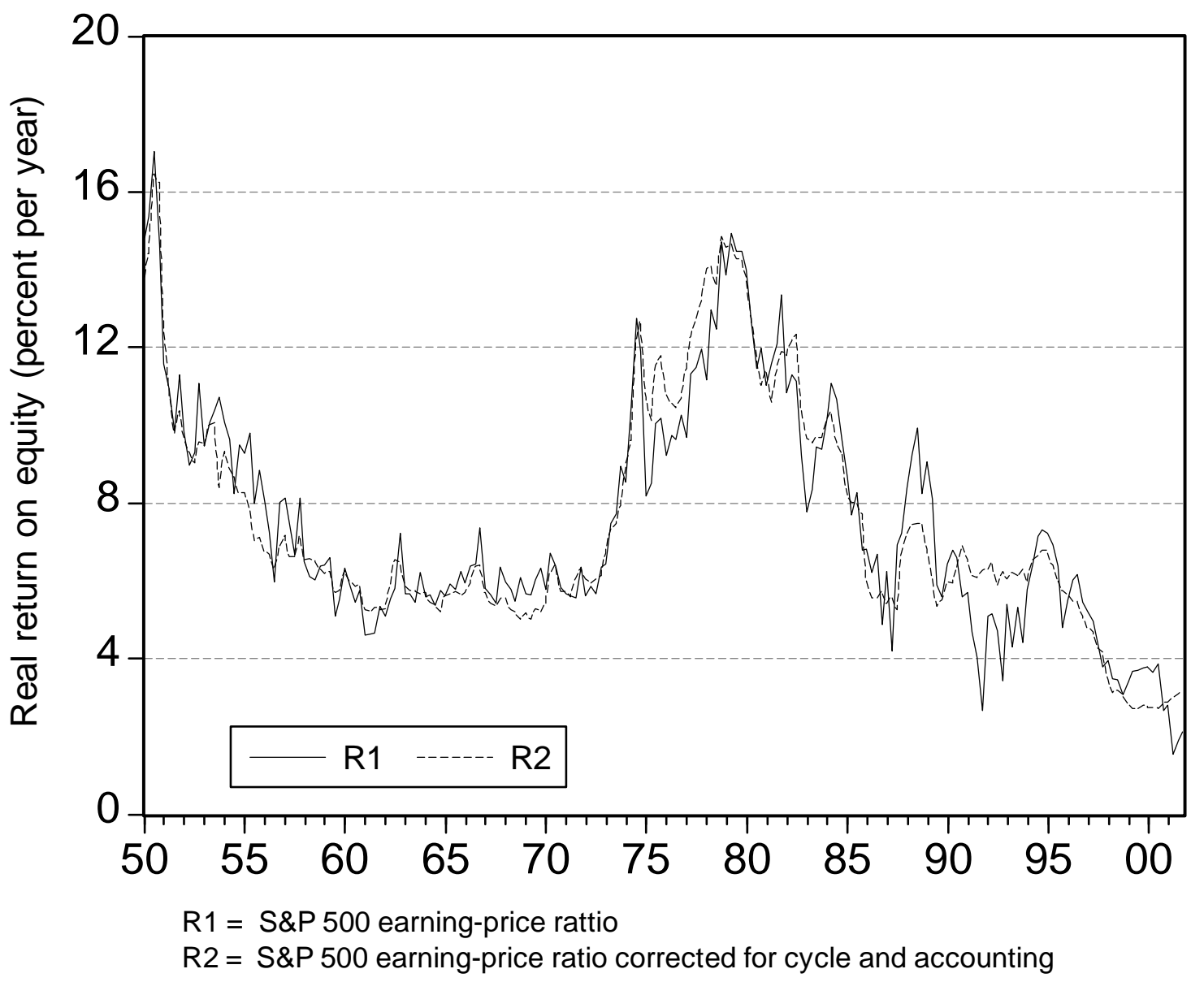

Figure 7. Alternative Measures of Forward-Looking Real Return on Equity, 1948-2001

This figure shows two alternative measures of the forward-looking or ex ante real return on equities. The solid line is the earnings-price ratio for the S\&P 500, measured as reported earnings in the current quarter divided by the S\&P 500 index for that quarter. The dashed line corrects reported earnings for the cycle and for accounting adjustments as described in the text. 


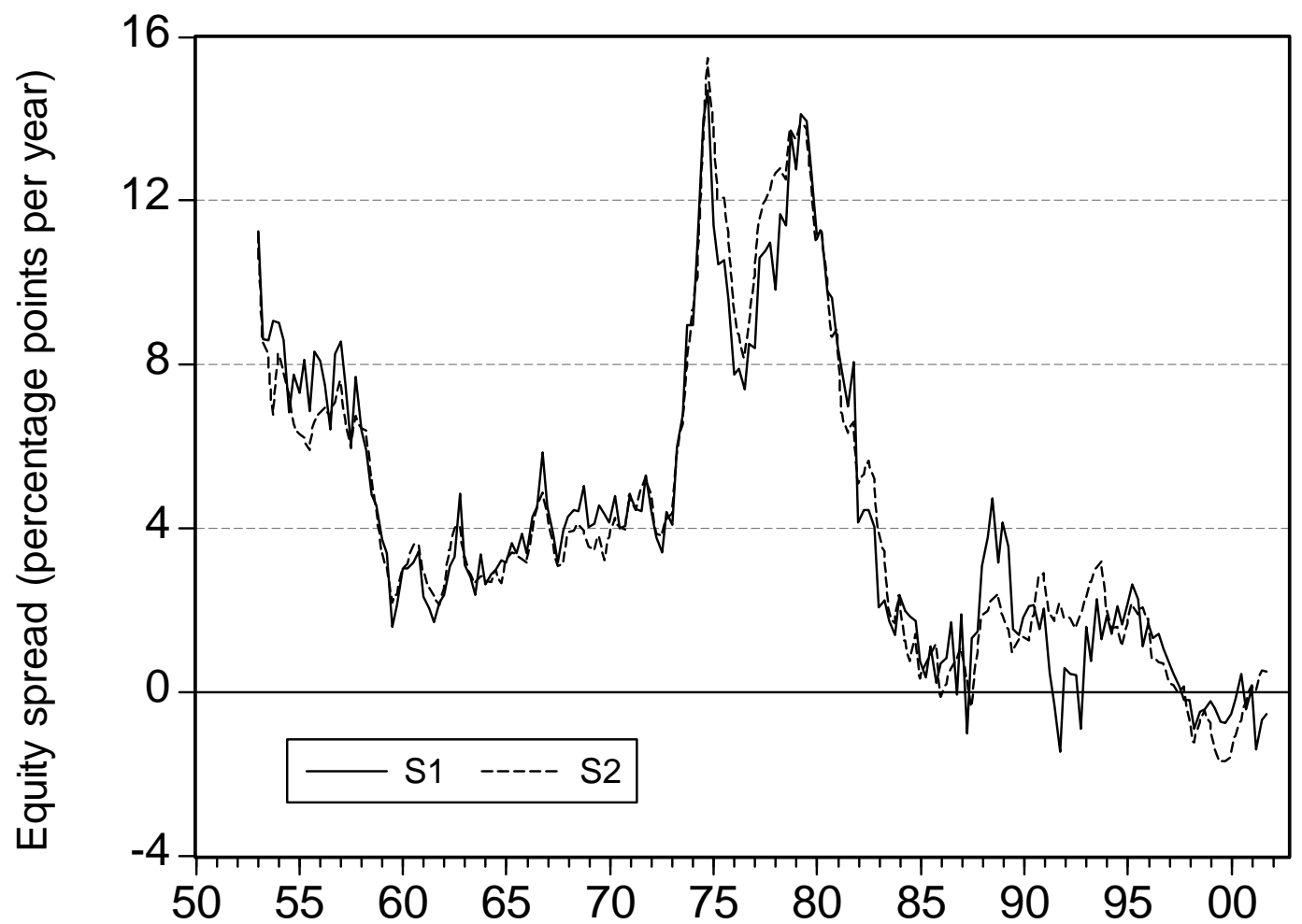

S1 $=$ Spread between S\&P 500 and real 10-year bonds (S\&P reported earnings)

S2 $=$ Spread between S\&P 500 and real 10-year bonds (S\&P earnings corrected for cycle and accounting)

\section{Figure 8. Equity Spread for Different Concepts, 1952-2001}

This figure shows two alternative measures of the spread between equities and bonds. The spread is defined as the forward looking real return on equities shown in Figure 7 minus the real interest rate on 10year Treasury bonds. The real interest rate corrects the nominal interest rate for movements in the GDP price index. The solid line uses the earnings-price ratio for the S\&P 500 (r1 in Figure 7) while the dashed line corrects reported earnings for the cycle and for accounting adjustments (as for r2 in Figure 7). 